\title{
Predictive values of Alvarado score, serum C-reactive protein, and white blood cell count in the diagnosis of acute appendicitis: a prospective study
}

Ademola Olusegun Talabi ${ }^{1 *}$ (D), Tewogbade Adeoye Adedeji², Oludayo Adedapo Sowande ${ }^{1}$ and Olusanya Adejuyigbe ${ }^{1}$

\begin{abstract}
Background: The diagnosis of acute appendicitis in children is quite challenging as the rate of negative appendectomy varies between 15 and 57\%. Increased utilization of imaging diagnostic facilities in advanced countries seems to have reduced the incidence of operating on normal appendix to a single digit. In low- and middle-income countries, the incidence remains unacceptably high (double digits). Inflammatory markers and scoring systems may be a suitable adjunct to increase diagnostic yield in most third world countries. Thus, the aim of this study was to evaluate the diagnostic value of Alvarado score, white blood cell count, and serum C-reactive protein in children with acute appendicitis.

Results: The ages of patients ranged between 4 and 15 years with a mean of $11.2 \pm 2.8$ years. The male to female ratio was 1.4 to 1.0. Nineteen percent of patients had negative appendiceal findings on histological examination. The sensitivity and specificity of Alvarado score, C-reactive protein estimation, total white blood cell count in diagnosing acute appendicitis were $86.4 \%$ and $63.2 \%, 98.8 \%$ and $36.8 \%$, and $51.9 \%$ and $89.5 \%$ respectively. Alvarado score has the highest area under ROC curve analysis $0.824,95 \% \mathrm{Cl}$ of 0.724 to 0.924 compared with CRP, $0.769 .95 \%$ $\mathrm{Cl}$ of $=0.647$ to 0.891 and WBC count, $0.765,95 \% \mathrm{Cl}$ of 0.643 to 0.887 . Both CRP and WBC count showed higher discriminatory values between complicated and uncomplicated appendicitis, $p<0.001$.

Conclusion: Alvarado score outperformed other tests in setting the diagnosis of acute appendicitis. However, none of the tests can be relied on wholly for operative decision. Clinical judgement remains the bedrock for diagnosis and operative management.
\end{abstract}

Keywords: Alvarado score, C-reactive protein, White cell count, Acute appendicitis

\footnotetext{
* Correspondence: ademolatalabi1608@gmail.com

'Department of Surgery, Obafemi Awolowo University/Obafemi Awolowo

University Teaching Hospitals Complex, lle-lfe, Osun State, Nigeria

Full list of author information is available at the end of the article
}

\section{Springer Open}

(c) The Author(s). 2021 Open Access This article is licensed under a Creative Commons Attribution 4.0 International License, which permits use, sharing, adaptation, distribution and reproduction in any medium or format, as long as you give appropriate credit to the original author(s) and the source, provide a link to the Creative Commons licence, and indicate if changes were made. The images or other third party material in this article are included in the article's Creative Commons licence, unless indicated otherwise in a credit line to the material. If material is not included in the article's Creative Commons licence and your intended use is not permitted by statutory regulation or exceeds the permitted use, you will need to obtain permission directly from the copyright holder. To view a copy of this licence, visit http://creativecommons.org/licenses/by/4.0/. 


\section{Background}

Acute appendicitis is one of the most common causes of abdominal surgical emergencies in children and adolescents [1]. Most workers advocate early diagnosis and quick surgical intervention so as to reduce morbidity and sometimes mortality associated with complications such as gangrene, perforation, and abscess formation [2, 3].

Early diagnosis is often based on history and clinical examination and sometimes aided by laboratory tests [4]. This approach usually results in unacceptably high negative appendicectomy rate as many conditions of the gastro-intestinal tract mimic acute appendicitis. On the other hand, atypical presentation is common in the relatively younger children and adolescent females. This may pose a serious diagnostic dilemma which can result in delayed intervention and consequently lead to increased incidence of complications. Previous studies indicated that the rate of negative appendicectomy varies from 15 to $57 \%[5,6]$.

A large number of scoring systems including Alvarado's score or its modification [7-10] have been developed to aid in the diagnosis with varying degrees of predictive values. Scoring systems are valuable and valid instruments of discrimination between acute appendicitis and non-specific abdominal pain [11]. The Alvarado score is the most well studied and best performing in validation studies, though it has some drawbacks [12]. Elevated white blood cell (WBC) count, with its differential count or neutrophil lymphocyte ratio has been shown to be helpful in the diagnosis of acute appendicitis. The advantages are that they are readily available and cheap. A more recently introduced laboratory biomarker is C-reactive protein (CRP). Its normal serum concentration is less than $10 \mathrm{mg} / \mathrm{dl}$. The evaluation of this protein is simple and its quantitative assessment aids in the diagnosis of acute appendicitis [13, 14]. However, other studies have concluded that neither normal nor raised CRP value is helpful in the diagnosis of acute appendicitis [14-16].

There is paucity of literature on the use of Alvarado score, WBC, and CRP in aiding diagnostic efficacy of acute appendicitis in our sub-region. Thus, this prospective study was conducted to evaluate the diagnostic value of Alvarado's score, CRP, as well as white blood cell count in children with clinical suspicion of acute appendicitis in OAUTHC Ile-Ife, Nigeria by assessing the sensitivity, specificity, positive predictive, and negative predictive values (PPV and NPV respectively) of these parameters in an inflamed appendix.

\section{Methods}

This was a hospital based prospective study conducted between January 2018 and December 2019 among children aged 15 years and below with clinical diagnosis of acute appendicitis. Approval to conduct the study was obtained from the Ethics and Research Committee (International: IRB/IEC/0004553; NATIONAL: NHREC/27/02/2009a) of our hospital while informed consent was gotten from the parents of the participating children. Consecutive patient with provisional diagnosis of inflamed appendix were enrolled into the study. Their biodata, relevant clinical history such as migratory right iliac fossa pain, number of episodes of vomiting, admission temperature, tenderness in the right iliac fossa, rigidity and rebound tenderness, were documented in a spread sheet. The laboratory tests, WBC/differential count, and CRP concentration were performed on blood samples collected at the time of admission. The serum CRP was estimated using an i-chroma Reader (which is a fluorescence scanning instrument) manufactured by Boditech Med Inc., Germany.

The Alvarado's score of each patient was determined by a combination of clinical and laboratory parameters. They were stratified into three risk groups based on their scores:

Group A: Alvarado score of 1-4

Group B: Alvarado score of 5-6

Group C: Alvarado score of 7-10

A score between 7 and 10 (Group C) was considered to be positive and predictive. The cut-off value for WBC counts was $>11,000 / \mathrm{cm}^{3}$. This value corresponds with elevated WBC (normal range 4$11000 / \mathrm{cm}^{3}$ in our environment). The cut-off value for CRP was taken as $>10 \mathrm{mg} / \mathrm{dl}$. The appendix was sent for histopathological examination. The pathological criterion for diagnosis of acute appendicitis was neutrophil infiltration of all layers of the appendicular wall. Based on histopathological findings, the appendicular specimen was divided into three categories: normal appendix (negative in macroscopic and microscopic finding of acute appendicitis), inflamed appendix (simple appendicitis), and suppurative/gangrenous/perforated appendicitis (complicated appendicitis).

Data were analyzed using IBM SPSS 21. Means (standard deviation) and frequencies were used to describe continuous variables, Student's $t$ test was used to analyze continuous variables while Chi-square test was used for analysis of categorical variables. Analysis of the diagnostic tests was performed to determine the sensitivity, specificity, positive predictive, and negative predictive values. A receiver operating characteristic (ROC) curve was used to determine the area under the curve (AUC) with a confidence interval of $95 \%$ and the best cut-off values for Alvarado score, WBC, and CRP. $\mathrm{LR}^{+}$and $\mathrm{LR}^{-}$ were calculated. A $p$ value less than 0.05 was deemed significant. 


\section{Result}

One hundred children with the clinical suspicion of inflamed appendix were enrolled into the study. There were $59(59 \%)$ males and $41(41 \%)$ females giving a male to female ratio of 1.4 to 1 . Their ages ranged between 4 and 15 years with a mean of $11.2 \pm 2.8$ years. Nineteen patients had normal appendicular findings on histopathological examination, giving a negative appendicectomy rate of $19 \%$. No mortality was recorded in this study. Of the 19 patients with normal appendicular findings on histology, there were 10 females and 9 males, $p$ $=0.337$. Among the cohort of children with histologically confirmed acute appendicitis $(n=81), 54(66.7 \%)$ presented after $24 \mathrm{~h}$ of onset of abdominal pain. There was a statistical significant difference between duration of symptoms and the development of complicated appendicitis, $p=0.001$ (Table 1). The mean Alvarado score for patients with appendicitis was $8.4 \pm 1.4$ while it was $5.8 \pm 1.4$ for those with normal histological findings, $p=$ 0.001. The mean serum CRP concentration for patients with acute appendicitis and those without were $207.0 \pm$ $154.7 \mathrm{mg} / \mathrm{dl}$ and $41.1 \pm 38.5 \mathrm{mg} / \mathrm{dl}$, respectively. The presence of an elevated CRP was also significantly associated with appendicitis $p=0.001$. Mean serum concentration of CRP for those with complicated appendicitis and simple appendicitis were $256.7 \pm 142.0 \mathrm{mg} / \mathrm{dl}$ and $128.6 \pm 144.0 \mathrm{mg} / \mathrm{dl}$, respectively, with a statistical significant difference, $p=0.004$.

The mean WBC count for those who had acute appendicitis and normal findings were $12824 \pm 6526 \mathrm{~cm}^{3}$ and $6246 \pm 1458 / \mathrm{cm}^{3}$, respectively. An abnormal WBC count was significantly associated with histological diagnosis of appendicitis, $p=0.001$. The mean WBC count of patients with simple appendicitis was $9562 \pm 3632.4 / \mathrm{cm}^{3}$ whereas it was $14573 \pm 7375.0 / \mathrm{cm}^{3}$ for those with complicated appendicitis, $p=0.001$.

Of the patients with a score between 5 and 6, 11 (55\%) had positive appendicitis, though the decision to operate was based on the discretion of the surgeon. In this group, there were 9 (45\%) patients in whom histology showed that the removed appendix was normal (Table 2). The correlation of Alvarado score, serum C-reactive protein and WBC with histology of appendix is highlighted in Table 3

Table 1 Relationship of duration of symptoms with the severity of acute appendicitis

\begin{tabular}{|c|c|c|c|}
\hline \multirow{2}{*}{$\begin{array}{l}\text { Duration } \\
\text { in hours }\end{array}$} & \multicolumn{2}{|c|}{ Acute appendicitis } & \multirow{2}{*}{$\begin{array}{l}p \text { value } \\
0.001\end{array}$} \\
\hline & $\begin{array}{l}\text { Complicated } \\
n(\%)\end{array}$ & $\begin{array}{l}\text { Simple (uncomplicated) } \\
n(\%)\end{array}$ & \\
\hline$\leq 24$ & $10(19.2)$ & $17(58.6)$ & \\
\hline$>24$ & $42(80.8)$ & $12(41.4)$ & \\
\hline
\end{tabular}

Table 2 Correlation between histological finding of appendix and risk stratification of Alvarado score

\begin{tabular}{|c|c|c|}
\hline \multirow[t]{2}{*}{ Alvarado score } & \multicolumn{2}{|c|}{ Histological finding of appendix } \\
\hline & $\begin{array}{l}\text { Positive for acute } \\
\text { appendicitis }\end{array}$ & $\begin{array}{l}\text { Negative for acute } \\
\text { appendicitis }\end{array}$ \\
\hline Low risk (1-4) & 0 & 3 \\
\hline $\begin{array}{l}\text { Intermediate risk } \\
(5-6)\end{array}$ & 11 & 9 \\
\hline High risk (7-10) & 70 & 7 \\
\hline
\end{tabular}

The sensitivity, specificity, PPV, and NPV of Alvarado score, WBC, and CRP is as shown in Table 4. The optimal cut-off value for Alvarado score was 7.0 with a sensitivity and specificity of $86.4 \%$ and $63.2 \%$, respectively. The optimal cut-off value for WBC was 9050 with a sensitivity and specificity of $65.4 \%$ and $89.5 \%$, respectively. Similarly, the best cut-off value of CRP to differentiate acute appendicitis from non-specific abdominal pain (non-appendicitis) on receiver operating characteristic curve was $42 \mathrm{mg} / \mathrm{dl}$ with a sensitivity and specificity of $85.2 \%$ and $52.6 \%$, respectively. The area under ROC curve for Alvarado score, WBC, and CRP were 0.824, 95\% CI of 0.724 to $0.924 ; 0.765,95 \%$ CI of 0.643 to 0.887 and $0.769,95 \% \mathrm{CI}$ of 0.647 to 0.891 , respectively (see Fig. 1).

The best cut-off CRP value that differentiated simple appendicitis from complicated appendicitis was $94.5 \mathrm{mg} /$ $\mathrm{dl}$ with sensitivity and specificity of $71.2 \%$ and $58.6 \%$, respectively, and an ROC value of $0.674,95 \% \mathrm{CI}=0.547$ 0.802. Among those with confirmed appendicitis, the best threshold for white blood cell count that differentiated simple appendicitis from complicated ones was $9300 / \mathrm{cm}^{3}$ with sensitivity and specificity of $73.1 \%$ and

Table 3 Relationship between Alvarado score, C-reactive protein, white blood cell count, and histopathology of the appendix

\begin{tabular}{llll}
\hline & \multicolumn{2}{l}{ Histopathology } & \\
\cline { 2 - 3 } Alvarado score & Acute appendicitis & Non-acute appendicitis & \\
\hline$\geq 7$ & 70 & 7 & 77 \\
$<7$ & 11 & 12 & 23 \\
Total & 81 & 19 & 100 \\
CRP & & & \\
$\quad \geq 10 \mathrm{mg}$ & 80 & 12 & 92 \\
$<10 \mathrm{mg}$ & 1 & 7 & 8 \\
Total & 81 & 19 & 100 \\
WBC count & & & 44 \\
$11,000 / \mathrm{cm}^{3}$ & 42 & 2 & 56 \\
$11,000 / \mathrm{cm}^{3}$ & 39 & 17 & 100 \\
Total & 81 & 19 & \\
\hline
\end{tabular}


Table 4 The sensitivity, specificity, PPV, and NPV of diagnostic tests

\begin{tabular}{|c|c|c|c|c|c|c|c|}
\hline & AP & WBC & CRP & $A P+C R P$ & $A P+W B C$ & $C R P+W B C$ & $A P+C R P+W B C$ \\
\hline Sensitivity & 86.4 & 51.9 & 98.8 & 96.3 & 96.3 & 100.0 & 96.3 \\
\hline Specificity & 63.2 & 89.5 & 36.8 & 42.1 & 26.3 & 26.3 & 47.4 \\
\hline PPV & 90.9 & 95.5 & 86.9 & 87.6 & 84.8 & 85.3 & 88.6 \\
\hline NPV & 52.2 & 30.4 & 87.5 & 72.7 & 62.5 & 100.0 & 75.0 \\
\hline LR+ & 2.35 & 4.93 & 1.56 & 1.71 & 1.31 & 1.36 & 1.83 \\
\hline LR- & 0.22 & 0.54 & 0.03 & 0.09 & 0.14 & 0.00 & 0.08 \\
\hline
\end{tabular}

$51.7 \%$, respectively, and an $\mathrm{ROC}$ of $0.704,95 \% \mathrm{CI}=$ $0.591-0.817$.

Sensitivity, specificity, PPV, and NPV were calculated in isolation for Alvarado score, WBC, and CRP. When these parameters were further evaluated by combining Alvarado score with WBC, CRP, and WBC and CRP, and finally combining all parameters (Alvarado score, WBC, and CRP) (Table 4), the specificity and PPV became lower after combining these variables than that of Alvarado score. Furthermore, sensitivity and NPV of the various combination did not yield any diagnostic improvement.

\section{Discussion}

The main findings of this study was that Alvarado score had the highest area under ROC curve, 0.824 compared with that CRP (0.769) and total white blood cell count (0.765), and all the above diagnostic tests only showed moderate discriminatory power for acute appendicitis. In addition, the CRP level, WBC count as an independent variable did not aid the diagnostic accuracy of Alvarado score in acute appendicitis in children.

The diagnosis of acute appendicitis still remains problematic due to unacceptably high negative appendicectomy rate in spite of the introduction of modern imaging techniques $[11,15]$. Though CT, ultrasound, and laparoscopy gave the best diagnostic accuracy in terms of high sensitivity and specificity, their use is fraught with many limitations: first, $\mathrm{CT}$ emits radiation that could lead to cancer in future; second, it is not costeffective in low-income countries in sub-Sahara Africa where most patients pay out of pockets; third, ultrasound on the other hand is dependent not only on the

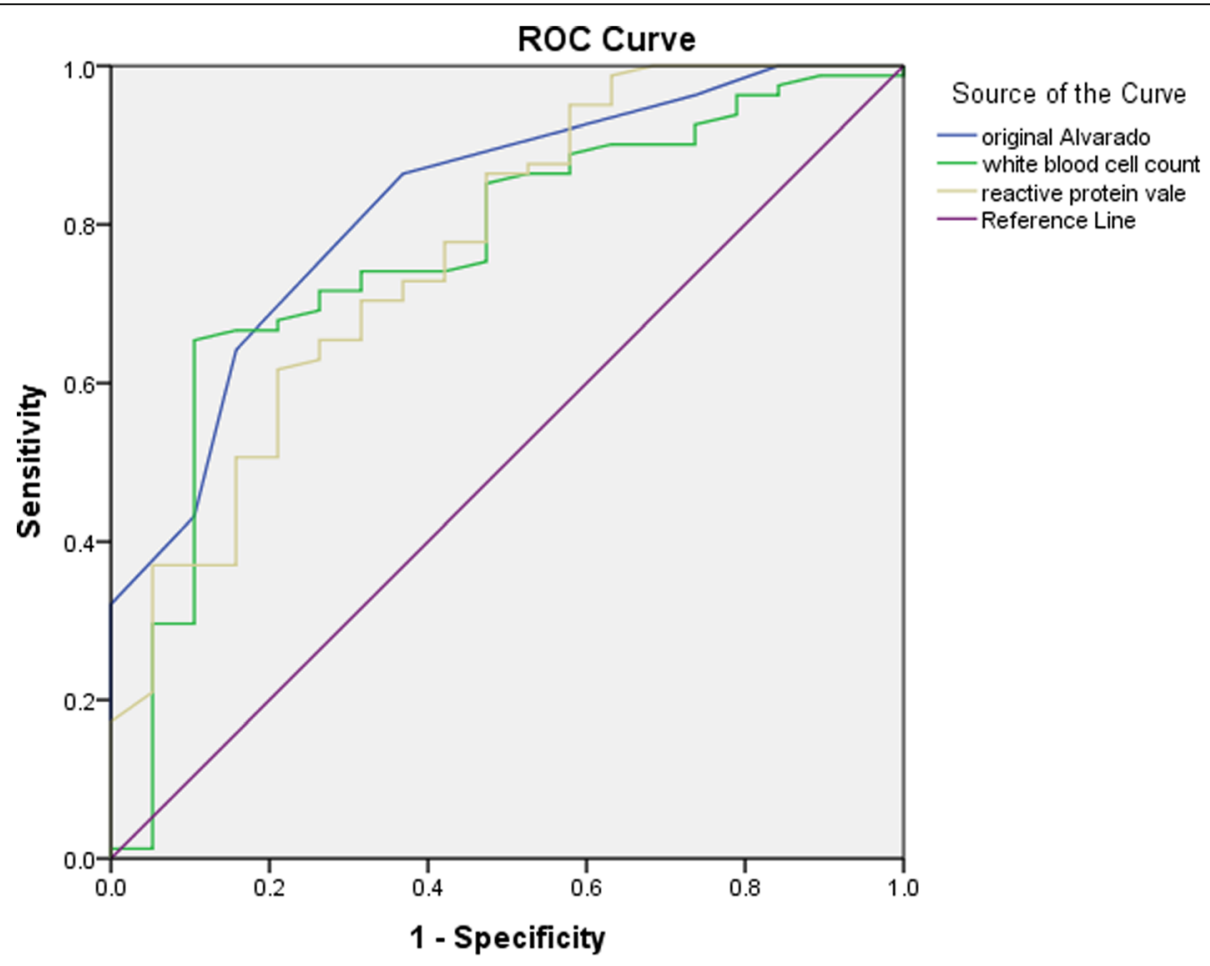

Diagonal segments are produced by ties.

Fig. 1 The area under ROC curve analysis of Alvarado score, C-reactive protein, and white blood cell count 
quality of the machine, but also on the operator, and inter-observer variation is a disadvantage $[13,15,17]$.

The predictive values of Alvarado score in the current study are consistent with the results obtained by Pogorelic et al.'s sensitivity, specificity, PPV of $89 \%, 59 \%, 93.1 \%$, and $46 \%$, respectively [5]. Dey et al., as well as Nanjundaiah et al., Al Awayshih and associates in mixed population studies also observed comparable findings $[4,11$, 18]. In this study, the decision to operate was based on the clinical judgement of the surgeon with a negative appendicectomy rate of $19 \%$ which was comparable to rates obtained in settings where CT scan is not routinely deployed in the diagnosis of acute appendicitis $[11,13$, 14]. The rate however drops to as low as $2.5-7.5 \%$ in settings where CT scan is routinely deployed $[19,20]$. The high positive predictive value of Alvarado score has an important clinical implication. A high positive predictive value has the potential of reducing negative appendectomy rate. In this study, the positive predictive value of Alvarado score was $90.9 \%$ and had the decision to operate on children with acute appendicitis been based on Alvarado score, the negative appendectomy rates which is a function of the positive predictive value could have been reduced to $9 \%$.

On the other hand, a low negative predictive value as in our series $(52.2 \%)$ has an important clinical relevance. This parameter, when low, has the tendency to cause delay in surgical intervention among patients who truly require appendicectomy. The NPV was low because 55\% of patients with true acute appendicitis were classified into the intermediate category. Patients in this category are either observed or made to undergo additional diagnostic tests such as ultrasound scan, laparoscopy, or computerized tomography scan which is more sensitive than ultrasound scan. Thus, we concur with the school of thought that patients with an Alvarado score of 5-6 should be admitted and monitored closely until there are convincing evidence either to operate or be discharged home with a proviso that should symptoms become more profound, they should represent for admission in the hospital. One main controversy of the Alvarado score is its applicability in pediatric population. This is simply because Alvarado score requires children to identify migratory pain, nausea, and anorexia which are symptoms that are not easily verified in the extremely young children. In a meta-analysis of 1635 children using a cut-off score of 5 (admit/observe criteria), Ohle et al. [21] reported a sensitivity of $99 \%$ and specificity of $57 \%$ which was similar to that of adult population. They also found out that at a cutoff score of 7 (surgical criteria), the sensitivity was $87 \%$ and the specificity was $76 \%$, thereby concluding that a similar clinical prediction can be used in children as well as in adults.
The other modalities of investigating acute appendicitis are laboratory markers. The contribution of the WBC count to the diagnosis of acute appendicitis in children is controversial [22]. Yang et al. [23] reported that WBC, CRP, and neutrophil count may assist in the diagnosis of acute appendicitis and that patients with normal values in all the three tests are highly unlikely to have appendicitis. Wu et al. [6] noted that WBC may serve as a predictive laboratory marker of early appendicitis in children. Other studies evaluating the role of WBC count in children with acute appendicitis reported that they are poorly reliable in confirming or excluding acute appendicitis [14, 17].. Elevated WBC count may be found in many patients with non-specific abdominal pain with inflammatory response, and up to $20 \%$ of patients with histopathology-proven appendicitis may present without leukocytosis [24]. In the present study, about $48 \%$ of patients with acute appendicitis presented without leukocytosis suggesting that total white blood cell count alone may not be an ideal test to screen patients with acute appendicitis. The reported sensitivity and specificity for WBC varies among studies, ranging between 70 and $90 \%$ and 44 and $78 \%$, respectively [3, 14, $25,26]$. In our series, the specificity of $89.5 \%$ was comparable to these studies. However, the sensitivity was disappointingly low $(51.9 \%)$ suggesting that WBC count would have missed a substantial number of patients with acute appendicitis. Although, there is no general consensus in the medical literature regarding which WBC cutoff values are optimal for maximizing predictive values, the cut-off established in the current study is comparable with that obtained by Bates et al. [27] who found that a WBC threshold of $9000 / \mathrm{cm}^{3}$ improved both the sensitivity in diagnosing appendicitis as well as reducing the false positive rate and increased specificity within their study population. Monsalve et al. [22] in a pediatric-based study found a cut-off of $15,000 \times 10^{9} / \mathrm{L}$ when the sensitivity and specificity were $65 \%$ and $68 \%$, respectively, for WBC. In this series, a significantly elevated WBC count was found in acute appendicitis compared to those with a normal appendix, and also that WBC was higher in complicated than in simple appendicitis and this is consistent with previous reports [22, 28]. WBC count appeared to be useful in differentiating between simple and complicated appendicitis with a discriminating threshold of $9300 / \mathrm{cm}^{3}$. However, the diagnostic accuracy of WBC in the current study is low thereby limiting the use of WBC count in decision making on whether to operate a child with acute appendicitis or not.

CRP is an acute phase reactant whose serum concentration increases in response to inflammatory processes. There are plethora of reports documenting the value of CRP in improving the diagnostic value of acute 
appendicitis. Shogilev et al. [15] noted that an increase in serum concentration of CRP occurs between 8 and 12 $\mathrm{h}$ after the onset of inflammatory process with a peak between 24 and $48 \mathrm{~h}$ which is later than that of WBC, thereby contributing little diagnostic value in the early phase of acute appendicitis. However, John et al. [13] are of the opinion that CRP is the earliest inflammatory marker whose concentration has been found to rise on repeated testing whereas leucocyte counts have been found to decrease. In spite of this contrasting observations, one of the major advantages of CRP is its ease of measurement and cost-effectiveness for rural communities where CT, MRI, and laparoscopy are not available. In a study of 542 patients [29], the ROC curve for CRP rises as the duration of symptoms increases from 0.60 on day 1 to 0.88 on day 3 while in cases of perforated appendicitis, there was a remarkable increase in ROC curve from 0.90 on day 1 to 0.96 on day 3 suggesting that CRP is a strong predictor of appendiceal perforation but is quite limited for appendicitis in general. The results of the present study highlighted that CRP, though not specific (36.8\%), is quite sensitive (97.5\%) with high positive and negative predictive values. Glass et al. [25] in a meta-analysis reported that the sensitivity and specificity of CRP ranged from 58 to $93 \%$ and 28 to $82 \%$, respectively. Shogilev et al. [15], in a review article, observed that when the best cut-off values of serum CRP to diagnose acute appendicitis was greater than $10 \mathrm{mg} / \mathrm{L}$, the sensitivity and specificity, ranged from 65 to $83 \%$ and 59 to $73 \%$, respectively. A study conducted by Zouari et al. [17] reported a sensitivity and specificity of $76.9 \%$ and $51.6 \%$, respectively. Agrawal et al. [14], in their series, found a sensitivity and specificity of $74.8 \%$ and $66.7 \%$, respectively. A much higher CRP sensitivity and specificity of $98 \%$ and $87 \%$, respectively, was recorded by John et al. [13] in a mixed-population study. A recent study [22] reported that the sensitivity and specificity of CRP in identifying complicated appendix were $74 \%$ and $74 \%$, respectively, at this cut-off of $361.9 \mathrm{umol} / \mathrm{L}$. Other studies $[1,15,22]$ reported an association between disease severity and CRP level. Chung et al. [30] reported that patients with complicated appendix had a significantly higher mean CRP compared with simple appendix (92 $\mathrm{mg} / \mathrm{dl}$ vs $31 \mathrm{mg} / \mathrm{dl}$ ) while Ghimire et al. found CRP > $85 \mathrm{mg} / \mathrm{dl}$ [1]. Thus, high CRP levels could possibly predict the diagnosis of complicated appendicitis and facilitate more appropriate surgical therapy [16]. Our finding agrees with these reports $[1,16,30]$. This implies that CRP appears to be helpful in identifying patients with complicated appendicitis but its predictive values in appendicitis are limited as a sole diagnostic investigation as alluded to by some researchers $[14,30]$.

In our study, we evaluated the predictive values of combining CRP, WBC count, and both with Alvarado score. The PPV and NPV of these diagnostic tools after combining results did not yield any improvement. This is consistent with the observations of previous studies [17, 24]. However, Stefanutti et al. [31], as well as Mekhail and associates [32], reported significantly higher predictive values when CRP was combined with WBC count in aiding diagnostic value of acute appendicitis in children.

\section{Conclusions}

Alvarado score may be of help in setting the diagnosis of acute appendicitis; however, none of the three diagnostic tests has sufficient predictive values in assessing acute appendicitis, and none can be used as an exclusive standard in setting the diagnosis of acute appendicitis in children. The final decision still rests on the opinion of a pediatric surgeon.

\section{Abbreviations}

MRI: Magnetic resonance imaging; CT: Computed tomography; AIR: Appendicitis inflammatory score; WBC: White blood cell; CRP: C-reactive protein; PPV: Positive predictive value; NPV: Negative predictive value; OAUTHC: Obafemi Awolowo University Teaching Hospitals Complex; ROC: Receiver operating characteristics; AUC: Area under curve; $L^{+}$: Positive likelihood ratio; $L R^{-}$: Negative likelihood ratio

\section{Acknowledgements \\ The authors would like to thank Professor FJ Owotade for assisting in data analysis. \\ Authors' contributions \\ All authors contributed to the study conception and design. Material preparation, data collection, and analysis were performed by AO Talabi, TA Adedeji, and OA Sowande. The first draft of the manuscript was written by AO Talabi, TA Adedeji, and OA dejuyigbe, and all authors commented on previous version of the manuscript. All authors read and approved the final manuscript.}

\section{Funding}

We received no funds to conduct the study. It was self-funded.

\section{Availability of data and materials}

The datasets generated and or analyzed during the current study are not publicly available but are available from the corresponding author on reasonable request.

\section{Ethics approval and consent to participate}

The Ethics and Research Committee of our institution approved the conduct of the study, Number; (International: IRB/IEC/0004553; NATIONAL:NHREC/27/ 02/2009a). A written informed consent was obtained from the parent and or legal guardian of every participant. This was part of the basis upon which ethical approval was given.

\section{Consent for publication}

Not applicable

\section{Competing interests}

The authors declare that they have no competing interests.

\section{Author details}

'Department of Surgery, Obafemi Awolowo University/Obafemi Awolowo University Teaching Hospitals Complex, lle-lfe, Osun State, Nigeria.

${ }^{2}$ Department of Chemical Pathology, Obafemi Awolowo University/Obafemi Awolowo University Teaching Hospitals Complex, Ile-Ife, Osun State, Nigeria. 
Received: 7 October 2020 Accepted: 4 February 2021

Published online: 10 March 2021

\section{References}

1. Ghimire R, Sharma A, Bohara S. ROLE OF C-reactive protein in acute appendicitis. Kathmandu Univ Med J. 2016;54:130-3.

2. TO A, Oludayo SA, Samuel OA, Amarachukwu EC, Akinwunmi KO, Olusanya A. Clinicopathological review of 156 appendicectomies for acute appendicitis in children in Ile-lfe, Nigeria: a retrospective analysis. BMC Emergency Med. 2015;15:7.

3. Joshi A, Dange S, Apturkar D, Saxena P. Study of values of C-reactive protein, total leukocyte counts and neutrophil counts in diagnosis of acute appendicitis. Indian J Basic Appl Med Res. 2017;7:59-61.

4. Dey S, Mohanta PK, Kharga B, Bhutia KL, Singh VK. Alvarado scoring in acute appendicitis - A clinicopathological correlation. Indian J Surg. 2010;72:290-3. https://doi.org/10.1007/s12262-010-0190-5

5. Pogorelic Z, Rak S, Mrklic I, Juric I. Prospective validation of Alvarado score and appendicitis inflammatory score for the diagnosis of acute appendicitis in children. Pediatr Emerg Care. 2015;31:164-8.

6. D Wu HP, Chen CY, Kuo IT, Wu YK, Fu YC. Diagnostic values of a single biomarker at different time points compared with Alvarado score and imaging examinations in pediatric appendicitis. J Surg Res. 2011; 174:272 277. doi: 10.1016/j.jss.2011.01.047

7. Podany AB, Tsai AY, Dillon PW. Acute appendicitis in pediatric patients: An updated narrative review. J Clin Gastroenterol Treat. 2017;3:042.

8. Patil S, Harwal R, Harwal S, Kamthane S. Appendicitis inflammatory response score: a novel scoring system for acute appendicitis. Inter Surg J. 2017:4: 1065-70.

9. Alvarado A. A practical score for the early diagnosis of acute appendicitis. Ann Emerg Med. 1986:15:557-64

10. Peyvasteh M, Askarpour S, Javaherizadeh H, Besharati S. Modified Alvarado score in children with diagnosis of appendicitis. Arq Bras Cir Dig. 2017;30: 51-2. https://doi.org/10.1590/0102-6720201700010014.

11. Al Awayshih MM, Nofal MN, Yousef AJ. Evaluation of Alvarado score in diagnosing acute appendicitis. PAMJ. 2019;34:15. https://doi.org/10.11604/ PAMJ.06/09/2019.34.15.17803.

12. de Castro SMM, Unlu C, Steller EP, van Wagensveld BA, Vrouenraets BC. Evaluation of the appendicitis inflammatory response score for patients with acute appendicitis. World J Surg. 2012;36:1540-5.

13. John SK, Joseph J, Shetty SR. Avoiding negative appendectomies in rural surgical practice: Is C-reactive protein estimation useful as a diagnostic tool? Nat Med J India. 2011;24:144-7

14. Agrawal CS, Adhikar S, Kumar M. Role of serum C-reactive protein and leukocyte count in the diagnosis of acute appendicitis in Nepalese population. Nepal Med Coll J. 2008:10:11-3.

15. Shogilev DJ, Duus N, Odom SR, Shapiro NI. Diagnosing appendicitis: evidence-based review of the diagnostic approach in 2014. West J Emerg Med. 2014;15:859-71. https://doi.org/10.5811/westjem/2014.9.21568.

16. Ahmed N. C-reactive protein: An aid for diagnosis of acute appendicitis. J Ayub Med Coll Abbottabad. 2017;29:250-3.

17. Zouari M, Jallouli M, Louari $H_{1}$ Kchaou R, Chtourou R, Kotti A, et al. Predictive value of C-reactive protein, ultrasound and Alvarado score in acute appendicitis: a prospective pediatric cohort. Am J Emerg Med. 2015. https:// doi.org/10.1016/j.ajem.2015.0.004

18. Nanjundaiah N, Ashfaque M, Venkatesh S, Kalpana A, Priva SA. A comparative study of RIPASA score and Alvarado score in the diagnosis of acute appendicitis. J Clin Diagn Res. 2004;8:NC03-5.

19. Pickhardt PJ, Lawrence EM, Pooler BD, Bruce RJ. Diagnostic performance of multidetector computed tomography for suspected acute appendicitis. Ann Intern Med. 2011:154:89-96.

20. Aspelund G, Fingeret A, Gross E, Kessler D, Keung C, Thirumoorthi A, et al. Ultrasonography/MRI versus CT for diagnosing appendicitis. Pediatrics. 2014; 133:586-94

21. Ohle R, O'Relly F, O'Brien KK, Fahey T, Dimitrov BD. The Alvarado score for predicting acute appendicitis: a systematic review. BMC Med. 2011;9:139.

22. Monsalve S, Ellwanger A, Montedonico S. White blood cell count and C reactive protein remain useful for diagnosis and staging of acute appendicitis in children. S A fr Med J. 2017:107:773-6. https://doi.org/10.71 96/SAMJ.2017.v107i9.12206.
23. Yang HR, Wang YC, Chung PK, Chen WK, Jeng LB, Chen RJ. Role of leukocyte count, neutrophils parentage and C-reactive protein in the diagnosis of acute appendicitis. Am Surg. 2005;71:344-7.

24. Gronroos P, Huhtinen H, Gronroos JM. Normal leukocyte count and Creactive protein value do not effectively exclude acute appendicitis in children. Dis Colon rectum. 2009;52:1028-9.

25. Glass CC, Rangel SJ. Overview and diagnosis of acute appendicitis in children. Seminars Pediatr Surg. 2016 doi: doi: https://doi.org/10.1053/j. sempedsurg.2016.05.001

26. Ali N, Rasul S, Mehmood Z, Khan IA. Value of total leucocyte count and Creactive proteins in the diagnosis of acute appendicitis. J Surg Pakistan (Int). 2009;14:153-6.

27. Bates MF, Khander A, Steigman SA, Tracy TF Jr, Luks Fl. Use of white blood cell count and negative appendectomy rate. Pediatrics. 2014;133:e39-44 www.pediatrics.org/cgidoi/10.1542/peds.2013-2418.

28. Tucker A, Sloan K, Gartsin I, Verghis R. White cell count, CRP and appendicitis - Is there a role for operative blood tests? A cohort study. Health Med Informat. 2015;6:185. https://doi.org/10.4172/2157-7420.1000185.

29. Wu HP, Lin CY, Chang CF. Predictive value of C-reactive protein at different cutoff levels in acute appendicitis. Am J Emerg Med. 2005;23:449-53.

30. Chung JL, Kong MS, Lin SL, Lin TY, Huang CS, Lin JN. Diagnostic value of Creactive protein in children with perforated appendicitis. Eur J Pediatr. 1996; 155:529-31

31. Stefanutti G, Ghirardo V, Gamba P. Inflammatory markers for acute appendicitis in children: are they helpful? J Pediatr Surg. 2007:42:773-6. https://doi.org/10.1016/j.jpedsurg.2006.12.028.

32. Mekhail P, Naguib N, Yanni F, Izzidien A. Appendicitis in paediatric age group: Correlation between preoperative inflammatory markers and postoperative histological diagnosis. Afr J Paeditr Surg. 2011;8:309-12.

\section{Publisher's Note}

Springer Nature remains neutral with regard to jurisdictional claims in published maps and institutional affiliations.

\section{Submit your manuscript to a SpringerOpen ${ }^{\circ}$ journal and benefit from:}

- Convenient online submission

- Rigorous peer review

- Open access: articles freely available online

- High visibility within the field

- Retaining the copyright to your article

Submit your next manuscript at $>$ springeropen.com 